\title{
Arquivo e memória: uma relação indissociável
}

\author{
Archive and memory: an inseparable relation
}

Dirlene Santos BARROS'

Dulce AMÉLIA²

\section{RESUMO}

Abordagem do arquivo e da memória como uma relação indissociável na sociedade da informação. Evidenciase tal relação como imprescindível, visto que o arquivo está impregnado de práticas e sentidos mnemônicos e rememorativos que compõem a identidade de um povo. Enfatiza-se a importância do arquivo como lugar para a realização da pesquisa histórica e para a produção do conhecimento. Criam-se, assim, novas formas de compreender os fenômenos e a maneira como eles se desenvolvem. Essa prática permite o cruzamento harmônico com a Ciência da Informação no que concerne a sua abordagem representacional. Enfoca-se, nesse processo, a relevância das fontes arquivísticas, que, ao serem inseridas no contexto socioeconômico, político e cultural, têm o ser humano como produtor de sentidos.

Palavras-chave: arquivo-memória; sociedade da informação; pesquisa histórica; documentos arquivísticos.

\begin{abstract}
Archive and memory approach as an inseparable relation within Information Society. This relation is evidenced as essential, thus the archive is imbued of practice and mnemonic and remindful senses that form the identity of a population. It is emphasized the importance of the archive as a place for achieving historic research and knowledge production; in such case, new ways of understanding the phenomena and the way they develop themselves are created. This practice allows the harmonious intersection with the Information Science concerning its representational approaching. It is focused the importance of the file source, which, when inserted in the social-economic, political and cultural context, points to the human being as a sense producer.
\end{abstract}

Keywords: archive-memory; information society; historic research; archivist sources.

\section{INTRODUÇÃO}

A sociedade da informação é um fenômeno universal, fruto do desenvolvimento da Pós-
Modernidade. É marcada pelo expressivo e crescente papel social da informação e pela grande potencialidade transformadora que exerce sobre os eixos econômico, social, cultural e político. A dinamicidade desses eixos,

\footnotetext{
1 Mestranda em Ciência da Informação, Programa de Pós-Graduação em Ciência da Informação, Centro de Ciências Sociais Aplicadas, Universidade Federal da Paraíba; bolsista da Fundação de Amparo à Pesquisa e ao Desenvolvimento Científico e Tecnológico do Maranhão - FAPEMA; e funcionária do Tribunal de Justiça do Estado do Maranhão. São Luis, MA. Coorespondencia para/Correspondence to: D.S. BARROS. E-mail: <dirsb@yahoo.com.br>.

2 Doutora em Ciência da Informação, Universidade Federal de Minas Gerais. Pesquisadora da Fundação de Amparo à Pesquisa e ao Desenvolvimento Científico e Tecnológico do Maranhão - FAPEMA; e professora associada do Departamento de Ciência da Informação do Centro de Ciências Sociais Aplicadas da Universidade Federal da Paraíba. E-mail: <damelial@gmail.com>. Recebido em 6/3/2008 e aceito pra pulicação em 15/12/2008.
} 
em alguma medida, é dependente da informação (Wersig, 1993).

A sociedade da informação tem como eixo uma nova e hegemônica concepção de desenvolvimento: a produção do conhecimento em um cenário de múltiplas interpretações por parte de seus atores sociais. É a tendência científica (Arruda, 1998).

Há, ainda, a tão presente tendência tecnológica, representada pelo contínuo desenvolvimento das Tecnologias de Informação (TI's) (Robredo, 2003) e pela conseqüente celeridade da sua própria obsolescência, que têm incidido sobre práticas e funções de instituições que registram a multifacetada herança cultural da sociedade e evocam a sua memória.

Nesses termos, uma das instituições envolvidas nesse processo - e será somente acerca desta que se irá refletir neste artigo - é o arquivo, mais precisamente o arquivo histórico ou permanente, concebido como um dos alicerces e lugar da informação e da memória.

$O$ arquivo torna-se parte constitutiva da sociedade da informação por buscar uma atuação em consonância com as tendências tecnológica e científica da sociedade, ou seja, em função de as tecnologias de informação não limitarem os conceitos do mundo vivenciado pelo ator social, uma vez que este ocupa vários espaços ao mesmo tempo, potencializando, assim, a transmissão da informação.

Há, assim, uma fragmentação dos acontecimentos pelo conjunto dos seus registros e, ao mesmo tempo, uma ausência de conhecimento da multiplicidade de informações existentes. Para Barreto (2007), ocorre uma desintegração e um afrouxamento simbólico da memória.

Nesse sentido, o arquivo potencializa-se, seja por assumir novas funções, seja por renová-las, pois, além de coletar, salvaguardar, preservar, armazenar e disseminar a informação - funções tradicionais -, proporciona sua reorganização em face às $\mathrm{Tl}^{\prime} \mathrm{s}$, de forma a promover o encontro do cidadão com a informação.

A memória, nesse contexto, torna-se objeto de estudo com dimensões que necessitam ser bem mais analisadas e compreendidas. Entenda-se, com esta afirmação, não apenas a compreensão das dimensões que compõem a memória, mas, sobretudo, a assimilação da forma como elas vêm-se transformando em elementos cada vez mais necessários para que seja possível trabalhar o passado e assimilar suas relações com a sociedade da informação.

Orquivo é visto aqui como um lugar em que a memória se torna participante do processo de identidade, como praxe e representação da sociedade da informação. Não se pretende com isso afirmar ser o arquivo a única instituição da memória, haja vista a existência de outras, como o museu, a casa de cultura etc. Neste trabalho, entretanto, enfoca-se apenas o arquivo. Ele é concebido, ainda, como elo com um passado de continuidade e de descontinuidade, que leva a aclarar suas dimensões sociais e suas contribuições diretas na organização da sociedade da informação.

O presente artigo aborda a relação entre o arquivo e a memória; aborda, também, o arquivo como um espaço de referência para a pesquisa histórica, ressaltando, nesse ponto, os documentos arquivísticos em que se buscam as relações existenciais entre o sujeito e a sociedade.

\section{ARQUIVO E MEMÓRIA: UMA RELAÇÃO INDISSOCIÁVEL}

A importância dos arquivos no mundo contemporâneo ganhou dimensões gigantescas, pois, com o desenvolvimento de conceitos sociais, econômicos, políticos e culturais da humanidade, a sociedade da informação - como fomentadora desse crescimento - cada vez mais exige do arquivo precisão nas informações fornecidas ao seu público-alvo.

Essa importância está diretamente relacionada aos aspectos históricos, jurídicos e administrativos, uma vez que, segundo Duranti (1994, p.50), "[...] através de milênios, os arquivos têm representado, alternada e cumulativamente, os arsenais da administração, do direito, da história, da cultura e da informação.".

O primeiro desses três aspectos - o histórico representa a memória de um povo, de uma instituição ou de um indivíduo, e, finalmente, constitui-se em fonte de pesquisa para todos os ramos do saber.

Bellotto (1989, p.81) afirma que: "[...] a finalidade última dos arquivos, seu objetivo maior, é, pois, comprovadamente, o acesso à informação, seja em que idade documental for e, conseqüentemente, em que âmbito arquivístico for." 
Dessa forma, a função básica do arquivo é tornar disponíveis as informações que estão sob a sua guarda no acervo documental, visto que o arquivo é "[...] um sistema bidimensional e nunca unidimensional. Nele se projecta com maior ou menor expressão a entidade produtora/receptora de informação [...]." (Silva et al., 2002, p. 40).

Percebe-se, então, que esse status do arquivo não condiz apenas com o testemunho da identidade de uma sociedade e, tampouco, com uma instituição de guarda e preservação dos discursos de um povo. Constituído em base sólida, sua atuação extrapola tais conceituações: ele é gerador de conhecimento. Por isso, ele se impõe como lugar indispensável para o exercício da pesquisa.

Orquivo torna-se um locus com essa especificidade, quando o pesquisador permite que os discursos partícipes desse meio se revelem pelo diálogo com outros diálogos ocorridos em diferentes épocas, de forma a estabelecer uma relação com a escuta do dito e, também, do não-dito. Tal assertiva é complementada por Novaes (1992, p. 9):

\begin{abstract}
Nossa história foi construída no esquecimento daquilo que Paul Valéry chamou de as duas maiores invenções da humanidade. $\bigcirc$ passado e o futuro. Sem passado e sem futuro, esta história oficial esvazia não apenas nossos pensamentos, mas principalmente a própria idéia de História. Narrar a história de um povo a partir apenas do tempo presente, tempo fragmentado, direcionado, "instante fugidio" tido como único tempo real, é negar a articulação de épocas e situações diferentes. O simultâneo tempo da história e o pensamento do tempo.
\end{abstract}

É o dito, a priori, que torna os acontecimentos únicos, ao estabelecer relações múltiplas, renovandose em face às rupturas e ao processo de complementaridade de outros acontecimentos. $\bigcirc$ arquivo torna-se ponto preponderante na atualização do que está dito com as outras facetas, pois são as coisas ditas que figuram como acontecimentos singulares, diferenciados em face de sua existência múltipla.

Além disso, é importante que se tenha consciência da complexidade da realidade. Isso reforça a necessidade de um estudo mais profundo sobre as normas que regem o arquivo, uma vez que os documentos só permitem o conhecimento de certo número de relatos, os únicos que emergiram graças à sua preservação nessa instituição chamada arquivo.

A complexidade do "sentido" do arquivo reforça a importância do seu estudo e de práticas de investigação histórica e documental face à necessidade de produção de conteúdos com base nas informações contidas em seus conjuntos documentais.

Orquivo, nessa compreensão, adquire uma nova postura, não apenas de guardião da memória, mas, sobretudo, como um espaço de referência da produção do conhecimento, que incita a efervescência da informação de maneira dinâmica e atualizada.

A partir daí, torna-se evidente que a relação entre memória e arquivo é imprescindível. Aquela tem este último como espinha dorsal. Tudo isso foi possível a partir da necessidade do homem de externar de forma física os pensamentos, quando passou a registrar seus feitos, eternizando informações que entendia como memoráveis. Segundo Lodolini (1989) apud GagnonArguin (1998, p.34):

desde a mais alta Antigüidade o homem sentiu
necessidade de conservar a sua própria
"memória", primeiro sob a forma oral, depois
sob a forma de graffiti e de desenhos, e,
finalmente, graças a um sistema codificado, isto
é, com símbolos gráficos correspondentes a
sílabas ou a letras. A memória assim registrada
e conservada constituiv e constitui ainda a base
de toda e qualquer actividade humana: a
existência de um grupo social seria impossível
sem o registro da memória, ou seja, sem
arquivos.

Assim, surge a memória registradora que delegou ao arquivo a função de mantê-la viva, de forma a desacelerar o desaparecimento dos sinais do que se deseja manter, em face da necessidade do lembrar.

Oarquivo, portanto, consagra-se como o locus que se mantém vivo e atuante no meio da sociedade que o teceu, permitindo, assim, a externalização e a mediação entre o tempo e os acontecimentos passados. Essa consagração é reafirmada por $\operatorname{Cook}(1998$, p. 148), quando ressalta que: 
Os arquivos são templos modernos - templos da memória. Como instituições, tanto como coleções, os arquivos servem como monumentos às pessoas e instituições julgadas merecedoras de serem lembradas. Igualmente, as que são rejeitadas, por serem julgadas não merecedoras, têm seu acesso negado a esses templos da memória e estão fadadas, assim, ao esquecimento de nossas histórias e de nossa consciência social.

Tem-se, pois, que o arquivo é um sistema de informação social que se materializa em qualquer tipo de suporte, sendo caracterizado, principalmente, pela sua natureza orgânica e funcional associada à memória. Desse modo, a principal justificativa para a existência do arquivo é a sua capacidade de oferecer a cada cidadão um senso de identidade, de história, de cultura e de memória pessoal e coletiva.

A memória está em voga não só como tema de estudo entre especialistas. Também a memória como suporte dos processos de identidade e reivindicações respectivas está na ordem do dia. [...] Palavras-chave são "resgate", "recuperação" e "preservação" - todas pressupondo uma essência frágil que necessita de cuidados especiais para não se deteriorar ou perder uma substância preexistente. (Meneses, 1999, p. 12).

Observa-se, assim, que a memória se apresenta como uma questão necessária na sociedade da informação, visto que atua como representação de fragmentos que mantêm uma coletividade e que permitem a edificação e a legitimação de uma identidade social, sendo "[...] processo, projeto de futuro e leitura do passado no presente [...]." (Jardim, 1995, p.2).

Segundo Pollak (1992, p. 211 ), a memória pode ser compreendida, em um primeiro momento, como um fenômeno individual. Contudo, o autor ressalva que ela deve ser vista "[...] como um fenômeno construído coletivamente e submetido a flutuações, transformações, mudanças constantes", consolidandose no espaço, no objeto, na imagem, no suporte.

Entretanto, não se pode nem se deve conceber a memória sob o prisma da memorização. A memória deve, sim, ser concebida como as práticas e os dizeres das sociedades consubstanciados nas informações que se mantêm sempre atuais, sem lapso de tempo, e que podem ser referenciadas, através dos espaços em que habitam e das relações que constroem com esses espaços, denominados lugares de memória.

"Lugares de memória" é uma expressão criada pelo historiador Pierre Nora (1993), que os concebe como marcos testemunhais de uma outra era: era das ilusões eternas e materializadas nos museus, arquivos, cemitérios, coleções, festas, aniversários, tratados, processos verbais, monumentos, santuários e associações.

Os lugares de memória são, antes de tudo, restos. A forma extrema onde subsiste uma consciência comemorativa numa história que a chama porque ela a ignora [...]. O que secreta, veste, estabelece, constrói, decreta, mantém pelo artifício e pela vontade uma coletividade fundamentalmente envolvida em sua transformação e sua renovação. [...]. Os lugares de memória nascem e vivem do sentimento de que não há memória espontânea. (Nora, 1993, p.13).

Para Nora (1993), esses lugares de memória não têm seu espaço minimizado pela materialização. Na realidade, correspondem ao material constituído de significados que se encontram em um plano abstrato, propiciando a busca e o encontro de vestígios capazes de fomentar mudanças nas práticas sociais.

$\mathrm{Na}$ verdade, esses lugares atuam como representações de fragmentos que mantêm, por artifícios, uma coletividade envolvida por transformações. Estabelecem relações de pertencimento a espaços que não são mais habitados, mas que tonificam a preservação do simbólico.

Dessa forma, o que se tem posto é que a relação entre os acontecimentos vividos e a sua transmissão produz memória; e o arquivo, aqui, se apresenta como uma das formas de difundi-la, por meio do registro informacional presente em seus documentos.

Nesse sentido, o arquivo é o lugar de memória para a pesquisa histórica. Concebido como locus interativo entre o pesquisador e o objeto, por meio da revisita e da equiparação das teorias existentes, o arquivo possibilita o progresso e a humanização destas teorias e, ao mesmo tempo, o cultivo do pensar crítico e criativo do pesquisador. Servindo-se, assim, do arquivo, o pesquisador constrói a sua própria produção, para 
responder ao desafio da socialização do conhecimento, conforme enfatiza Foucault (2000, p. 26):

[...] as margens de um livro jamais são nítidas nem rigorosamente determinadas: além do título, das primeiras linhas e do ponto final, além de sua configuração interna e da forma que the dá autonomia, ele está preso em um sistema de remissões a outros livros, outros textos, outras frases: nó em uma rede.

Assim compreendido, o arquivo - como lugar de memória - dá vida aos documentos por meio da análise do discurso do que está posto e do que está oculto, tocando no mais íntimo dos acontecimentos. Por essa ação, cria-se um elo temporal e espacial que bloqueia qualquer ação na direção do esquecimento.

Todos esses aspectos contribuem para caracterizar o arquivo como um espaço de referência para a pesquisa histórica, que busca estabelecer um estudo crítico ao investigar os múltiplos discursos existentes no arquivo. Esse arquivo, sendo um lugar para a construção de tal saber, é o mediador que permite o acesso do pesquisador ao objeto da pesquisa, ampliando, dessa forma, as possibilidades de avanço para o exercício da produção do conhecimento.

\section{PESQUISA HISTÓRICA E DOCUMENTOS AR- QUIVÍSTICOS}

A pesquisa histórica tem sido uma necessidade ímpar para a formação e a solidificação da produção intelectual nas Ciências Humanas e Sociais. Essa singular importância da pesquisa histórica deve-se não apenas ao fato de ela servir para a apreensão de um conhecimento instrumental, mas, também, devido ao fato de remeter à prática de novas abordagens que conduzam à compreensão da realidade.

Esse campo se enriquece quando interage com as outras áreas do conhecimento, sempre preservando. porém, os espaços de cada uma das áreas envolvidas, e, ao mesmo tempo, ressaltando a riqueza e a dinamicidade de sua ação interdisciplinar.

É indiscutível a força vital dessas interações que estudam as práticas locais e a sua inserção social e política, quando interagem com os instrumentos, as concepções e os saberes contidos nas fontes documentais, conforme ressalta Foucault (2000, p.7):
[...] desde que existe uma disciplina como a história, temo-nos servido de documentos, interrogamo-los, interrogamo-nos a seu respeito; indagamos-lhes não apenas o que eles queriam dizer, mas se eles diziam a verdade, e com que direito podiam pretendêlo, se eram sinceros ou falsificadores, bem informados ou ignorantes, autênticos ou alterados. Mas cada uma dessas questões e toda essa grande inquietude crítica apontavam para o mesmo fim: reconstituir, a partir do que dizem estes documentos - às vezes meiaspalavras -, o passado de onde emanam e se diluiu, agora, bem distantes deles; o documento sempre bem tratado com a linguagem de uma voz agora reduzida ao silêncio: seu rastro frágil, mas, por sorte, decifrável.

Sob essa visão, torna-se possível pesquisar os processos de geração de conhecimento por meio do sujeito cognoscente, na busca de explicar a interação entre o sujeito que realiza ciência, o objeto construído e a representação do saber.

Além desses aspectos, inclui-se também a linguagem, o método e a concepção de que a legitimação do conhecimento é gerada social e historicamente, visualizando a pesquisa sob o ponto de vista do contexto, das circunstâncias e como produto das relações de fatores sociais, políticos, econômicos e culturais.

A compreensão desse panorama permite o cruzamento harmônico com a Ciência da Informação, no que concerne à sua abordagem representacional, visto que tal enfoque proporciona "[...] introduzir a informação na esfera do humano, no contexto do conhecimento e da linguagem." (Gonzalez Gómez, 2002, p. 1).

Dentro desse contexto, o arquivo emerge como locus dinamizador da prática da pesquisa histórica, com o objetivo de possuir em seu cerne as muitas linguagens que compõem o real, representado pela diversidade de tipos documentais. Dessa forma, os conjuntos documentais do arquivo são constituídos de elementos que "[...] funcionam como um inconsciente cultural, que assume um papel decisivo, e que intervêm para orientar uma apreensão, um conhecimento [...] profundamente baseado nas lutas imperialistas do momento." (Clavel-Lévèque, 1974 apud Le Goff, 2003, p.537). 
Contudo, o processo investigativo do pesquisador, como um usuário ávido pela recuperação da informação desejada, não se encerra nas informações contidas nesses documentos, pois se desdobra na análise dessas informações diante de um contexto, de uma situação.

Visto assim, os documentos arquivísticos constituem peças fundamentais para a pesquisa histórica e, conseqüentemente, para a materialização do conhecimento.

Em um sentido amplo, lidar com documentos arquivísticos na pesquisa histórica significa trabalhar com a produção de sentidos: estabelecendo interpretações sobre as condições em que foram produzidos; regulamentando movimentos; incentivando ou reprimindo discursos que vão se associar à maneira como se constroem significados; e tentando explorar o desenrolar dessa produção na busca do ponto central com a informação produzida.

Com base nesse entendimento, concebe-se documento arquivístico como um bem cultural patrimonial, emanado do saber e da memória da humanidade, com sentidos determinados pelas posições ideológicas colocadas em jogo no processo sóciohistórico em que as palavras são produzidas.

$\bigcirc$ documento arquivístico figura, desse modo, como um fenômeno da produtividade de informação, a qual, por sua vez, opera em tensão constante com o novo, o diferente. Aquilo que, em determinado momento, é dito de uma maneira diferente engendra transformações nos processos de significação, gerando rupturas na verdade que fora cristalizada por meio do processo de repetição.

Para Foucault (2000, p.7), o significado de documento arquivístico passou por uma metamorfose no campo histórico. Essa transformação, que continua acontecendo até os dias atuais, precisa ainda ser aperfeiçoada: "[...] o documento, pois, não é mais, para a história, essa matéria inerte, através da qual ela tenta reconstituir [...] o que é passado e o que deixa apenas o rastro [...]."

pensamento de Foucault consubstancia uma nova dimensão para o documento: ser visto não apenas como aquilo que diz a verdade por meio da interpretação, mas que precisa ser analisado no seu âmago e elaborado de forma a escutar a informação expressa e a não expressa.

Essa crítica, na realidade, possibilita uma superação no que concerne ao processo de produção do conhecimento, uma vez que tal produção se encontra ancorada em uma estrutura de informação caracterizada por inclinações pessoais e determinações globais que limitam seu campo em determinado contexto.

Esse conhecimento estaria apoiado no suporte institucional do arquivo e sob o fluido de um universo alterável e temporal, cujas oscilações teriam como condicionantes os imperativos sociais, políticos, econômicos e culturais que pautam o construto da ciência e do saber como um todo.

Assim, os documentos arquivísticos se constituem em fontes de informações indispensáveis a ser interpretadas, analisadas e cotejadas. Eles são obras humanas que registram, de modo fragmentado, informações ricas e complexas sobre relações coletivas. São interpretados, então, como exemplos de modos de vida, de concepções de mundo, de possibilidades construtivas específicas de contextos e de épocas, sendo estudados tanto na sua dimensão material como na sua dimensão abstrata e simbólica, que tornam efervescente a produção do conhecimento na sociedade da informação.

\section{CONSIDERAÇÕES FINAIS}

O estudo da compreensão, no sentido amplo, de memória produz um debate instigante, sobretudo porque o termo "memória" está inserido nos mais diversos ramos do conhecimento. Isso gera tanto uma gama de interpretações no cerne de cada área como um estreitamento de relações com estas áreas.

Dentre os saberes que mobilizam a noção de memória, destaca-se a Arquivística, que busca a identificação de aspectos salutares para a formação e para o amadurecimento em face da sociedade da informação.

O desenvolvimento da memória, aqui considerada como condição primordial para a formação e a consubstanciação da identidade individual e/ou coletiva, compreende sua transição das tradições orais para a sua produção moderna nas sociedades como um todo, por meio do documento.

Esse contexto, portanto, faz com que o arquivo não se reduza à mera instituição de guarda da memória, mas extrapole tal função. Ele representa um forte meio necessário para a definição social e cultural, assumindo, assim, uma postura de mediação na conquista de direitos, no que tange à aquisição de informações e à criação de novos conhecimentos. 
ARRUDA, M.C.C. Reflexos do processo de globalização na capacitação profissional. Informação \& Sociedade: estudos, v.8, n. 1, p. 11-24, 1998.

BARRETO, A.M. Memória e sociedade contemporânea: apontando tendências. Revista ACB, v.12, n.2, p.161-176, 2007.

BELLOTTO, H.L. Arquivologia: objetivos e objetos. Arquivo: boletim histórico e informativo, v. 10, n.2, p. 81-83, 1989.

COOK, T. Arquivos pessoais e arquivos institucionais: para um entendimento arquivístico comum da formação da memória em um mundo pós-moderno. Revista Estudos Históricos, v. 11 , n.21, p.129-149, 1998. Tema: arquivos pessoais.

DURANTI, L. Registros documentais contemporâneos como provas de ação. Revista Estudos Históricos, v.7, n. 13, p.49-64, 1994.

FOUCAULT, M. A arqueologia do saber. 6.ed. Rio de Janeiro: Forense Universitária, 2000.

GAGNON-ARGUIN, L. Os arquivos, os arquivistas e a arquivística: considerações históricas. In: ROUSSEAU, Jean-Yves et al. Os fundamentos da disciplina arquivística. Lisboa: Publicações Dom Quixote, 1998.

GONZALEZ GÓMEZ, M.N. Dos estudos sociais da informação aos estudos do social desde o ponto de vista da informação. In: AQUINO, M.A. (org.). Ciência da Informação: gênese, especificidade e conexões. João Pessoa: Editora Universitária, 2002. p. 1-17.
JARDIM, J.M. A invenção da memória nos arquivos públicos. Ciência da Informação, v.25, n.2, 1995.

LE GOFF, J. História e memória. 2.ed. Tradução de Bernardo Leitão et al. Campinas, SP: UNICAMP, 2003.

MENESES, U.T.B. A crise da memória, história e documento: reflexões para um tempo de transformações. In: SILVA, Z.L. (org.). Arquivos, patrimônio e memória: trajetórias e perspectivas. São Paulo: UNESP/FAPESP, 1999

NORA, P. Entre memória e história: a problemática dos lugares. Trad. Yara Aun Khoury. Projeto História, n. 10, p.7-23, 1993.

NOVAES, A. (org.). Tempo e história. São Paulo: Companhia das Letras, 1992.

POLLAK, M. Memória e identidade social. Revista Estudos Históricos, v.5, n. 10, p.200-212, 1992.

ROBREDO, J. Da Ciência da Informação revisitada aos sistemas humanos de informação. Brasília: Thesaurus: SSR Informações, 2003.

SILVA, A.M. et al. Arquivística: teoria e prática de uma ciência da informação. 2.ed. Porto: Afrontamento, 2002.

WERSIG, G. Information science: the study of postmodern knowledge usage. Information Processing and Management, v.29, n.2, p.229-239, 1993. 
